\title{
POÉTICA Y POEMA (POR EJEMPLO EN OCTAVIO PAZ)
}

Que toda poesía implica una poética es cosa tan obvia que apenas vale la pena formularla. Pero establecer distinciones y relaciones internas en esa afirmación simplista tal vez no sea tan ocioso. Una primera distinción, apenas menos palmaria, resultaría sin esfuerzo de una ojeada histórica. En la poesía occidental aparece con claridad, desde el romanticismo, un corte que separa dos diferentes maneras de relación entre poesía y poética. Antes de esa época, como después de ella, la obra de todo poeta se apoya en una ida de la poesía, que es tanto un programa como un conocimiento, tanto una voluntad consciente como una tendencia oscura. Pero de uno y otro lado de esa frontera histórica cambia el papel individual del poeta frente a la idea de la poesía. Del lado de allá, el poeta individual no tiene prácticamente nada que decir en el debate, real o virtual, de la poética. Si su obra de poeta, como tal, ha de contribuir de alguna manera a cambiar (o acaso a confirmar y estructurar) la poética imperante, será de modo indirecto, por lo general mediante movimientos de elementos periféricos y aislados, y casi siempre involuntariamente. La acción de un poeta sobre la idea aceptada de la poesía será por acumulación de pequeñas mutaciones inevitables, casi imperceptibles tomadas una por una, de tal manera que cada uno podrá pensar mantenerse estrictamente fiel al programa heredado mientras lo somete, al realizarlo, a mínimos desplazamientos que acabarán -sumándose unos a otros cientos o miles de veces- por desfigurarlo enteramente. Del romanticismo para acá, la cosa es bien distinta. La poética se pone en tela de juicio en cada obra, en su centro mismo, y el poeta, en el poema mismo, tiene que tomar personalmente posición.

Así resumida, la fórmula puede parecer exagerada. Es cierto que este radical cuestionamiento, incesantemente renovado, de la idea misma de poesía en cada poeta, y aun en cada poema o al menos en cada "época" de una evolución, sólo se manifiesta plenamente en tiempos muy recientes, y que es tal vez una mirada 
excesivamente actual la que concibe según esa perspectiva la obra de los primeros románticos. Creo que esa mirada se justifica no sólo porque la interrogación sobre la poesía está efectivamente presente, aunque quizá menos visiblemente, en esos poetas, sino además porque la serie de eslabones que nos unen a ellos forma un continuo, mientras que entre esa época y la anterior hay discontinuidad. Quiero decir que nuestra mirada y la de los primeros románticos no son dos miradas, son dos momentos de una misma mirada.

Podemos pues pasar a una segunda distinción, esta vez sin tener en cuenta la evolución histórica. Ha sido rozada ya en los párrafos precedentes. Se trata de qué podemos entender por la poética de un poeta, por la idea de poesía incluida en toda obra poética. Es fácil distinguir de inmediato una poética voluntaria y explícita de una poética involuntaria e implícita. Una cosa son los programas, los razonamientos, las posiciones declaradas de un poeta, y otra la oscura representación inconsciente (expresión discutible), las tendencias no confesadas, los supuestos no buscados que puede uno intentar descubrir tras la primera apariencia de sus poemas efectivos.

Las páginas que siguen dan por supuesta la primera distinción. Pienso que no es preciso insistir mucho sobre el carácter crítico de la poesía moderna, que vio ya claramente Baudelaire y que no creo que nadie niegue, por lo menos hasta cierto punto y desde cierta época. No creo en cambio que pueda darse por supuesta la segunda distinción. Sería arbitrario decidir de antemano si existe, o aun si es posible, alguna discrepancia entre la intención estética explícita y la implícita de una poesía. Aun aceptando que existe una lectura sintomática del sentido inconsciente de un poema, me parece claro que esta lectura es psicológica y no estética; que es justamente sintomática, es decir que no lee la poesía, sino que lee en la poesía otro texto, como podemos leer en el timbre de voz de un hablante extranjero un síntoma del sexo al que pertenece, sin haber entendido por ello una palabra de lo que dice en su lengua. No nos interesa aquí ni siquiera discutir si esa lectura sería segura, y si no podríamos leer por ejemplo en el timbre de voz de una Marlene Dietrich una viril gravedad, o en el de algún menudo tenor una graciosa feminidad. Es otra la lectura que buscamos, y en ésta nada nos asegura que la intención del poeta no sea, precisamente, idéntica al poema. Por otra parte, sería también posible que la estética del poema y la estética del poeta no coincidan. Que una lectura, incluso no psicológica o aun no sintomá. tica nos conduzca a una idea de la poesía que el propio poeta en algún otro nivel contradice. Este otro nivel podría ser el del poema 
mismo. Si la poesía moderna es, en efecto, poesía crítica, debe ser posible describirla como poesía y crítica. Es probable que la división, por lo menos aplicada a verdaderos poemas, sea artificial. Pero ¿qué operación crítica no lo es en alguna medida? $\mathrm{E}$ incluso artificial, la distinción puede ayudarnos a representarnos más claramente una polaridad que, por su parte, tal vez no sea ella misma artificial. Es cierto que un poema es ante todo una unidad, pero no es menos cierto que esta unidad es compleja. Aunque las tensiones que pueden existir en el interior de esa complejidad sean tensiones internas, mientras que la descripción sólo podrá representarlas como tensiones entre polos que se son mutuamente exteriores, no parece imposible sin embargo que esta representación irreal arroje alguna luz sobre la organización real del poema o acaso de la poesía en general.

Podemos pensar por ejemplo en la poesía de Octavio Paz para referir a ella estas reflexiones, para buscar allí esa posible tensión, en el poema mismo, entre poesía y poética; entre lo que el poema quiere decir y quiere ser como realización encarnada de una poética, y lo que la poética sin querer dice y es, como supuesto implícito del poema. Apoyándonos, naturalmente, en la medida de lo posible, en la obra poética misma, con el mínimo de ayuda, aunque sin excluirlos del todo, de los escritos críticos y teóricos del poeta.

La obra de Octavio Paz es tal vez particularmente rica en este sentido. No sólo porque su poética ha sido siempre bastante explícita -y no me refiero a sus libros ensayísticos, sino a la poética incluida o supuesta en los poemas mismos- sino también porque esa poética ha evolucionado visiblemente, a la vez que evolucionaba visiblemente su estilo, y esas dos evoluciones han mostrado siempre un paralelismo especialmente claro. Apenas habrá tiempo de sugerir de modo muy sumario algunos rasgos sueltos de esa evolución, sobre todo porque no es eso lo que nos interesa en este momento, sino más bien apuntar a algunas preguntas sobre las relaciones entre la estética de un poema y la corporeidad misma de ese poema.

Es sabido que la exigencia crítica más elemental es la de intentar juzgar la obra, no según unas normas exteriores, sino según las intenciones que la obra misma manifiesta. Desde que existe una crítica propiamente dicha, existe el alegato de que la crítica no es normativa (incluso cuando de hecho lo es), y de que sus juicios no aplican escalas de valor fijadas de antemano, sino desprendidas de la observación y la comprensión de la obra misma. Esto implica que la obra no se compara con algún modelo previo, sino con su propio modelo, en ella misma incluido: la obra se compara consigo misma, desdoblando su sentido en dos o más sen- 
tidos separables. Nada podría decirse de una obra de arte, desde el momento en que renunciamos a las normas y modelos fijados previamente, si no la opusiéramos a ella misma, si no comparáramos la medida del desajuste por el cual puede no coincidir consigo misma.

En buena crítica, este desajuste no debemos verlo entre las actitudes voluntarias y razonadas del poeta, incluso expresadas en el poema, y el sentido que el poema como tal, en su conjunto y específicamente, nos muestra o creemos que nos muestra. Debemos verlo -más consecuentes con el presupuesto crítico que nos prohibe aplicar un modelo exterior, incluso si es el modelo propuesto por el autor mismo- entre ese sentido específico por un lado, y el modelo que de esa especificidad misma, clara o confusamente, inferimos. Un ejemplo burdo: no basta que un poeta declare, incluso en el interior de un poenı: "Yo escribo para todos", para que el poema esté efectivamente dirigido a todos. Nosotros, a la lectura, podemos juzgar que la verdadera intención del poeta, a despecho de sus declaraciones, era escribir por ejemplo para el estrecho círculo de sus amigos. Pero a su vez este segundo descubrimiento tampoco basta para que esa segunda intención se cumpla cabalmente. Ese poeta puede, mintiendo o mintiéndose sobre su verdadero programa, fracasar también respecto de este último. Otros ejemplos un poco más reales: Manuel José Othón puede protestar que su estética es arrtimodernista, y puede hacerlo imcluso en su poesía misma, o Neruda que la suya es de estricta ortodoxia marxista; esto por supuesto no nos autoriza, pero tampoco, justamente, nos desautoriza, a pensar que el programa efectivo de Othón, cuando escribe poesía, es más o menos modernista, o el de Nernda más o menos romántico o surrealista. Precisamente lo más habitual es juzgar a estos dos poetas sobre estos programas $\mathrm{u}$ otros parecidos. Juzgarlos, es decir comparar sus realizaciones con una estética inscrita en los poemas mismos, que no sólo no coincide necesariamente con las teorías razonables del poeta -que no son, después de todo, sino una interpretación más de su poética efectiva-, sino que tampoco implica necesariamente su propia realización; una estética que podría frustrarse en el acto mismo en que únicamente existe.

La frustración de un acto por sí mismo en su actuación misma: tal vez pueda pensarse que esta fórmula es propiamente la definición del inconsciente. En todo caso, lo sería en un sentido distinto del habitual. Frustrar no querría decir aquí impedir, ni siquiera dejar incompleto un acto o hurtarle sus frutos. Esa frustración se referiría al sentido del acto $\mathrm{y}$, más precisamente aún, a la pureza de $u n$ sentido único. Incluso en la acepción psíquica de la palabra 
sería burdo pensar que el inconsciente roba su sentido a la conciencia: añade otro sentido que la conciencia ignora, pero deja intacto el que ella asume. Lo único que queda frustrado es la pretensión de la conciencia representativa de que el sentido que ella asume es el sentido, el único sentido y todo el sentido.

Este descubrimiento -o esta búsqueda- de otros sentidos, que frustran las pretensiones al monopolio del sentido de la representación consciente, me parece característico de una corriente central del pensamiento moderno, que me atreveré a llamar así: el avance hacia una teoría generalizada del Inconsciente con mayúscula. Se ve que este Inconsciente con mayúscula no es lo mismo que el inconsciente psíquico, cuyo concepto, que debería servir de puente hacia una visión más general, se convierte a menudo en nuestros días, por demasiado, y demasiado superficialmente, repetido, en un velo difícil de apartar y que empaña esa visión. Mientras que la importancia que la lingüística actual ha tomado como guía y modelo de un estilo de pensamiento se debe a que ha sido la primera en sugerir otra faceta de la idea de inconsciente, al proponer lo que podríamos resumir con esta fórmula pintoresca: el inconsciente es la gramática.

Pienso que este laborioso rodeo nos ha apartado de nuestro tema menos de lo que podría parecer. Es bien sabido que la poética efectiva de Octavio Paz -la que llamaré poética incorporada para disínguirla de la otra, de la voluntaria y teórica, la de los libros ensayísticos-; es sabido, decía, que esta poética incorporada ha conservado a través de sus cambios una constante: la preocupación por la Palabra y por las palabras. No quiero decir, por supuesto, que esta preocupación, y otras de su poética incorporada, no se encuentren igualmente, y aun a menudo idénticamente, en sus teorías literarias. Quiero decir que para verla operando en el interior del poema, sólo debemos considerarla en la medida en que, presente o no en las teorías, esté efectivamente incorporada en la escritura poética misma. Pienso que para ningún lector atento de Paz será necesaria una larga demostración de que así es; citaré únicamente, y un poco al azar, el poema "Las Palabras":

Dales la vuelta,

cógelas del rabo (chillen, putas),

azótalas,

dales azúcar en la boca a las rejegas,

ínflalas, globos, pínchalas,

sórbeles sangre y tuétanos,

sécalas,

cápalas,

písalas, gallo galante,

tuérceles el gaznate, cocinero, 
desplúmalas,

destrípalas, toro,

buey, arrástralas,

hazlas, poeta,

haz que se traguen todas sus palabras ${ }^{1}$.

Independientemente de que podamos descubrir aquí una idea previa que coincide con ideas expresadas en los escritos teóricos, no cabe duda de que el poema es también la expresión poética de una real experiencia vivida: la relación del poeta con las palabras no es sólo una representación racional; ha sido incorporada, incluso si fue originalmente una representación tal, a la experiencia poética misma, por la vía de una experiencia vivida.

Pero esta preocupación de Paz por las palabras no es sólo una reflexión propia del oficio; o por mejor decir, es una reflexión sobre el oficio que se radicaliza hasta trascenderse, que lanza hacia arriba la copa de sus ramajes hasta abolir sus propias aríces y arraigar en otro suelo. No insistiré sobre la evolución de la obra de Paz desde una poesía de la soledad hacia una poética de la comunión, que ha sido descrita por Ramón XIRau en Tres poetas de la soledad ${ }^{2}$. Subrayaré más bien, paralelamente a esa descripción, la distancia entre la poética cercana al surrealismo (por ejemplo la

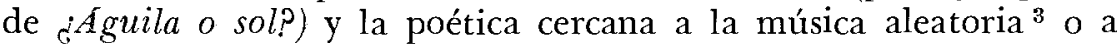
las teorías de la polisemia de un Jakobson o de un Barthes que podemos inferir de los Topoemas o los Discos visuales. Pero sólo subrayaré esa distancia para sugerir que deberíamos poder encontrar entre esos polos un centro virtual que los hace justamente polos de un mismo campo de fuerzas. Por que del surrealismo a la polisemia, lo que hay en común es esta búsqueda en la palabra de lo que podríamos llamar una pluralidad indecidible del sentido. Veremos más adelante en que sentido podríamos encontrar un paralelo, sin duda lejano, entre esa actitud y lo que nuestro examen podría sugerirnos para la poesía.

Antes conviene volver un poco atrás y recapitular sobre lo que este desarraigo de la intención significa para el poema. Porque podríamos decir de la intención estética que pone en marcha a la escritura lo que decíamos hace un momento de la preocupación del oficio en Octavio Paz. A esa poética incorporada le sucede en efecto lo mismo: en su propio movimiento se arranca de su suelo inicial y echa raíces en otro sitio. Ell acto de significación -o sea

1 Libertad bajo palabra, F.C.E., México, 1960, pp. 122-123.

2 Retomado en la primera parte de Octavio Paz: el sentido de la palabra, México, 1970.

3 Cf. por ejemplo el poema "Lectura de John Cage" (Ladera este, México, 1969, pp. 80-84). 
en general todo acto humano concebido como humano- es ese acto que al realizarse desplaza su propio origen, es ese río que al correr mueve su propio manantial.

En la naturaleza misma de la significación está inscrita esa no coincidencia, no sólo del significado con el significante, sino también (tal vez por ello mismo) del lazo que los une consigo mismo: del significar consigo mismo. Este descentramiento de la significación nos permitiría concebir de una nueva manera las diferentes manifestaciones de lo inconsciente. No sería necesario así oponer consciente $\mathrm{e}$ inconsciente como dos entidades sustanciales que se anulan mutuamente, ni atribuir el verdadero ser a una sola de ellas, de la que la otra no sería sino la máscara. Lo inconsciente no sería sino el exceso mismo de lo consciente, la no coincidencia de la significación y la representación consigo mismas, la imposibilidad de la conciencia de contenerse a sí misma por entero, la naturaleza misma de un conocimiento que nunca se conoce del todo. Esto nos permitiría también concebir diferentes grados de inconciencia, cosa al parecer difícil para la concepción habitual del inconsciente. Para poner un ejemplo superficial: la poética incorporada podrá considerarse inconsciente con respecto a la poética teórica (llamémosla estética), puesto que, originada en ésta, desplaza su propio origen al realizarlo; pero podrá considerarse consciente con respecto a la corporeidad misma del poema, puesto que esa corporeidad desplaza también inevitablemente la intención poética misma con que ese poema preciso inició su movimiento. $Y$ hay más todavía: invirtiendo la visión, la corporeidad del poema puede enfocarse a su vez como consciente respecto de su poética - puesto que esa poética es el esquema virtual, el "código", como está de moda llamarlo, de ese "mensaje", o sea su "gramática", y la gramática, como desde Saussure nadie ignora, es inconsciente. ¿Quiere esto decir que la relación entre estos grados es enteramente reversible? Quisiera aplazar por ahora la respuesta a esta pregunta, que es tal vez la pregunta fundamental sobre el problema todo de la significación.

Antes prefiero volver un poco atrás y mirar de nuevo desde el punto donde nos encontramos a una cuestión anterior y menos abstrusa que éstas en que ahora nos debatimos. Todas nuestras consideraciones sobre el carácter descentrado de la significación podían encontrarse ya en germen, como vimos, en esa idea tan sencilla y casi perogrullesca de la crítica más elemental: la idea de comparar la obra consigo misma. Pero ahora podemos ver una diferencia importante entre aquella idea de la obra y esta que hemos tratado de precisar, pues la comparación que la crítica elemental practica de la obra consigo misma es puramente negativa. 
La crítica más "neutral", "objetiva", "de comprensión", o como quiera llamársela, no podrá nunca ser otra cosa, en el mejor de los casos, que un recuento del desplazamiento de la intención estética concebido como medida del fracaso. Por eso esta crítica no puede encontrar ninguna obra perfecta: suponiendo que su reconstrucción de la poética incorporada sea exacta, un examen también exacto de su realización en la obra tendrá que encontrarla siempre traicionada. Esta fatalidad no es sin embargo invencible. El descentramiento del poema puede verse como su naturaleza misma, empezando por leerlo en ambas direcciones: como ruptura del sentido consciente de las palabras por irrupción de sentidos inconscientes: su poética o gramática estética ( $\mathrm{y}$ también, si se quiere, su gramática o estructura psicológica -entre otras-, puesto que una vez rota la hegemonía de un sentido todos los demás entran por la brecha, y esa es la razón de que un poema se ofrezca mucho más a las interpretaciones, psicoanalíticas por ejemplo, que, digamos, un tratado de entomología); y como ruptura del sentido consciente de la poética por irrupción de los sentidos inconscientes con que las palabras mismas, los ritmos mismos, y también los temas y hasta las ideas mismas desplazan la pura intencionalidad estética de que nacieron. Digámoslo así: un poema amatorio no puede hablar del amor sin convertirlo en un pretexto para la realización de una poética; ese mismo poema no puede realizar esa poética sin decir algo sobre el amor, sin nombrar al amor, y sin nombrarlo no sólo en abstracto, sino de esta o la otra manera, dándole este o aquel nombre. Si el poema integra en sí de veras estos dos aspectos, en él se revela que esa poética era sin saberlo un arte amatoria y esa arte amatoria sin saberlo una poética. Cada una de esas caras es una lectura de lo inconsciente de la otra.

La preocupación por la palabra de Octavio $\mathrm{Paz}$ (o de todo poeta, diría yo incluso) me parece que es una búsqueda o una vislumbre de esta configuración del significar en su naturaleza misma. No se trata, él lo ha dicho muchas veces, de las palabras de los filólogos, de los críticos y aun de los lingüistas. A pesar de su libro sobre Lévi-Strauss, a pesar de la estética combinatoria de los Discos visuales y de la estética a la vez polisémica y orientalista de Blanco, Octavio Paz está aun hoy más lejos del estructuralismo de lo que suele pensarse. Los versos de "Retórica", incluidos en Bajo tu clara sombra (op. cit., p. 77) no han sido negados del todo:

Cantan los pájaros, cantan

sin saber lo que cantan:

todo su entendimiento es su garganta. 
La forma que se ajusta al movimiento no es prisión, sino piel del movimiento.

3

La claridad del cristal transpartente no es claridad para mí suficiente:

el agua clara es el agua corriente.

Estos versos expresan una retórica de la transparencia del significante, de la adecuación de la expresión a un contenido que de una manera o de otra le es independiente, bastante alejada de las teorias más o menos jakobsonianas de la función poética como mensaje sobre el mensaje y como pura forma que no "dice" más que su propia estructura -necesariamente muda. Es cierto que en la primera estrofa se manifiesta también una poética del inconsciente. Pero es el inconsciente de los románticos y no de los estructuralistas. Los pájaros, los poetas, no saben lo que cantan. Lo sabe por ellos su garganta. Basta con pensar que mi garganta es más yo que mi razón para que pueda volver a decir que sé lo que canto. La metáfora, lo sé, es suficientemente ambigua para sufrir varias interpretaciones; podría no ser incluso una metáfora, sino una metonimia, y la garganta sería entonces el canto: así el canto se entendería a sí mismo y otra vez estamos en la significación que se significa. Pienso sin embargo que en esa época y ese tono la garganta es más del pájaro que del canto, y por ello el canto a su vez más del cantor que de sí mismo. No es lo mismo decir "en mi lenguaje me entiendo" que decir "a mí que no me entiendo me entiende un lenguaje al que no entiendo". No es lo mismo decir "la Palabra se inventa y me inventa cada día", que que decir "invento la Palabra, libertad que se inventa y me inventa cada día" (op. cit., p. 10).

Pero no es lo más importante lo que este poema declare sobre la retórica; lo más importante es lo que la poesía de $\mathrm{Paz}$ hace con estas declaraciones. Aunque ha ido probablemente tan lejos como cualquier otro poeta de nuestra lengua en su tentativa de poner en práctica una poética de anulación de los sentidos y de circularidad de la significación, símbolo de una metafísica de anulación de los contrarios y de vacuidad del sentido, su poesía efectiva no ha dejado de estar nunca en aquella línea del salto de la soledad a la comunicación que él mismo definió en sus primeros escritos teóricos, como su vida real no ha dejado de desplegarse bastante lejos del ascetismo, la renuncia o la anulación de la persona en la 
iluminación. Si la influencia budista ha sido grande en el útlimo Paz, también lo ha sido la del hinduismo. El Bhagavad Gita enseña a "no renunciar a los actos, sino al fruto de los actos"; enseña no el éxtasis sino la sabiduría; no la anulación del mundo sino la vuelta a él después de ese paso por la muerte que es la iluminación y la caída de las ilusiones. Como toda iniciación, ese libro enseña no a entrar en la muerte sino a volver de la muerte. La caida de la hegemonía ilusoria del sentido enseña igualmente a $\mathrm{Paz}$ no a entrar en el silencio, como las iluminaciones le enseñaron a Rimbaud o la muerte sin fin y sin salida final a José Gorostiza, sino a volver a las palabras, porque el poema es posible en ese espacio imposible de las significaciones, del mismo modo que la vida es posible en este mundo imposible.

Poética y poema están, pues, efectivamente, si no en oposición, sí en tensión en la obra de Octavio Paz. Pero si dejamos de ver esa tensión como una frustración, efecto negativo de las limitaciones humanas, etc., tal vez se nos muestre como la naturaleza misma del poema El poema corre siempre el riesgo de ser devorado por la poética. Contrariamente a lo que cree el poeta vulgar y afirmado en valores seguros, es devorado con mucha mayor seguridad cuando la poética, hecha invisible por el mágico manto del consenso y la aceptación indiscutida, digiere todo el poema sin que su feliz autor se percate siquiera de ello. Contra esta plácida digestión el poeta radical opone otra manera de enfrentar ese riesgo. La tensión llevada a su extremo entre poética y poema pone al poema constantemente al borde del abismo; la caída en ese abismo sería otra forma de devoración. Si no hay caída, estamos ante un gran poeta. No me atrevería a afirmar que todos los grandes poetas son de este género, pero sé que hay por lo menos una clase de grandes poetas que lo son no a pesar, sino porque su poética es insostenible

He dejado sin contestar una pregunta y sin completar una alusión. Quisiera, para terminar, sugerir - no podría hacer nada másen qué dirección me parece que podrían buscarse esa respuesta y ese complemento. Se ha mencionado con frecuencia, a propósito de Octavio Paz, a Saussure, a Lévi-Strauss, a Jakobson, a Chomsky. Se olvida que la lingüística moderna tiene, como todos nosotros, dos progenitores. A Saussure me gustaría más llamarle la madre de esa nueva prole que parece ser de padre desconocido, no porque no conste quién es, sino porque tantos de sus descendientes lo desconocen. Ese padre es un antipático danés llamado Louis Hjelmslev. Los estructuralistas franceses que tantas ideas han tomado desordenadamente de su patrimonio, tienen por lo general 
buen cuidado de citar, sin el molesto artificio de poner comillas, cualquier parte de sus escritos menos las conclusiones. Porque Hjelmslev deduce, con ese rigor heroico que tantos lectores le ha quitado, de las premisas que otros utilizan con cualquier fin, que la digestión de un metalenguaje por otro no es una serie infinita, que la significación no es circular y que las series de sentidos plurales no son indecidibles. Esto, naturalmente, impediría al señor Roland Barthes sostener que no sólo su libro $S / Z$ es otra versión del Sarrasine de Balzac, sino que esta nouvelle no es sino otra versión de $S / Z$. Y ya tenemos a Hjelmslev ignorado. Porque para nuestro molesto danés los metalenguajes son estrictamente limitados. A partir de la 3 a potencia deja de ser posible crear un metameta-metalenguaje, porque éste se confundiría, por un lado, con la nada excitante fonética, tan tradicional como acústica y articulatoria, por otro lado con la no mucho más excitante lógica * Mientras que la metapoesía sería... el poema mismo. Esto último no lo dice literalmente así. Lo dice de un modo más escandaloso aún. De un modo que razona con ejemplar simplicidad que las más elementales reglas binarias de la semiología implican que la poesía pueda hablar de cualquier cosa menos de la poesía; que el contenido de un lenguaje poético puede ser cuaquier cosa menos el lenguaje poético ${ }^{5}$. La reversibilidad de un orden de significaciones no es pues infinita: la significación se trasciende $\mathrm{y}$ esta trascendencia se llama el sentido ${ }^{6}$. Aquí, por supuesto, empezaría otra reflexión, demasiado espinosa para asomarnos siquiera a ella en

4 "En otras palabras, la metasemiologia [3a potencia en la terminología de Hjelmslev] es, en la práctica, idéntica a la llamada descripción de la sustancia. La tarea de la metasemiología es emprender un análisis autoconsecuente, exhaustivo y de la mayor simplicidad posible, de las cosas que aparecen para la semiología [ $2^{a}$ potencia] como individuos irreductibles (o entidades localizadas) del contenido, y de los sonidos (o de los signos escritos, etc.), que aparecen para la semiología como individuos irreductibles (o entidades localizadas) de la expresión" (L. HJelmslev, Prolegómenos a una teoría del lenguaje, trad. de J. L. Díaz de Liaño, Madrid, 1974, p. 172; los subrayados son de Hjelmslev).

5 Para la connotación no se puede hablar de una "metaconnotación", sino de una metasemiótica que evidentemente toma a la semiótica connotativa como plano del contenido y no como plano (de $2^{9}$ potencia) de la expresión: "A esta metasemiótica corresponde la tarea de analizar los diversos sentidos del contenido..." (HJelmsLev, op. cit., p. 173; el subrayado es mío). Sobre lo que Hjelmslev entiende por sentido, cf. infra, nota 6. Cf. también: "La semiótica connotativa, por tanto, es una semiótica que no es una lengua... Se trata, por tanto, de una semiótica en la que uno de los planos (el de la expresión) es una semiótica" (p. 166). Podemos añadir que el otro (el del contenido) no es pues una semiótica.

6 "Por sentido entendemos una clase de variables que manifiesta más de una cadena en más de una sintagmática, y/o más de un paradigma en más de una paradigmática" (p.153). 
este momento. Contentémonos con ver cómo los límites de la rever* sibilidad pueden apreciarse también en nuestro pequeño sistema ternario estética-poética-poema. Allí vimos cómo la poética podía ser el descentramiento del sentido de la estética, y el sentido que es descentrado por el poema. Pero es claro que estas relaciones no son simétricamente reversibles. Porque si bien la intencionalidad de la poética y la corporeidad del poema se quitan mutuamente la hegemonía en cuanto al sentido de los sentidos, no por ello dejan de ser radicalmente diferentes en su relación: la poética termina en el poema, mientras que el poema no termina en la poética. Pensemos por ejemplo en Blanco: es esto lo que explica que tantos lectores a quienes escapa por completo la estética del poema, así como la filosofía que funda esa estética, puedan sin embargo participar de la experıencia poética misma, de la corporeidad de sus palabras que dicen más que la regla de su combinación.

Sería demasiado arriesgado buscar un puente entre Chomsky y Hjelmslev, y no lo intentaré siquiera. Pero señalaré por lo menos que también la idea del lenguaje con que Chomsky renueva la lingüística rompe de otra manera el círculo de la reversibilidad. Porque vuelve a recordarnos, a pesar de que a veces se dice lo contrarıo, que no puede describirse el lenguaje olvidando que los hombres se comunican a través de él, y no ai revés. No es verdad, quiero decir que no es la única verdad, que Blanco dialogue con otros poemas u otras poéticas a través de Octavio Paz. Tal vez el poeta ha logrado esa ruptura del aislamiento del yo (que es otro asunto) : en ese caso tal vez no hablaría él a través de Bıanco; pero hablaría "el hombre". "El hombre" habla a través de su poesía tanto como la poesía habla a través del hombre. Sólo por eso puede la poesía ser una experiencia de iluminación o de trascendencia del yo; de otro modo se iluminaría sola y se trascendería en una soledad suya que no creo que pueda llamarse un yo y ni siquiera una inmanencia. Blanco está al borde del abismo, y ese abismo es el de la reversibilidad infinita e indecidible de las significaciones. Pero por la corporeidad de las palabras Blanco desemboca en nosotros y en el mundo, está vertiéndose en nosotros en un "chorro de evidencias" que descentran esa intención significativa al encarnarla. Ese chorro es el sentido, y el sentido, aunque no puede fijar en sí misma como a una cosa a la significación, simplemente porque no puede abarcar nunca de una vez la totalidad de las significaciones, impide sin embargo que su no coincidencia se propague en cadena hasta vaciarse de sí misma, y lo impide dándole esta dirección que hace de ella un movimiento orientado. Así la experiencia del vacio de la significación se convierte en eso: en una experiencia, es decir en un sentido-para-nosotros, como la expe- 
riencia de la vacuidad de la vida es una sabiduría y no una disolución. Las palabras reflejadas unas en otras de que hablaba Mallarmé se reflejaban ante todo, obviamente, en ese mismo Mallarmé. Así también lo que las palabras se dicen sólo constituye al poema porque "las palabras se dicen" quiere decir ante todo: "nos dicen que se dicen". El silencio de la Palabra se frustra en las palabras; a la vez se nos da en esas palabras; pero las palabras se dan en sí mismas, y sin frustrarse nos dan el silencio: lo nombran. Y la respuesta final la tiene una vez más Hölderlin: la poesía nos permite manipular el fuego del cielo, la ardiente luz de los inmortales, los dadores de sentido. En ella bebemos el rayo: unión del agua y del fuego. He aquí otra manera de entender esa unión de los opuestos: el "agua quemada" de los aztecas que le gusta a Octavio Paz.

Tomás SEgovia

El Colegio de México. 